\title{
Research assessment's ups and downs
}

The funding councils of the United Kingdom have achieved high standards in assessing, and thereby raising, the research performance of British universities. But dangers in the process merit further analysis.

SPARE a thought for the panellists involved in the third research assessment exercise (RAE) just carried out by British university funding councils (see Nature 385, 2; 1996). Carrying out the assessment of all university departments in their respective disciplines was burdensome enough. Now, returning to their desks after a seasonal break, they will have been assailed by telephone calls from friends and perhaps some freshly minted enemies seeking feedback on or justification for their decisions.

But in general the signs are that the panellists can reflect on a job well done. Cries of outrage have been understandably vigorous from those who feel their departments have been underrated but those appear to be few in number. The process whereby up to four publications per staff member over a period of four years were judged alongside editorships, plenary talks and the like appears to have evolved to a point where the community perceives a fair trade-off between adequate refinement of the assessments and workloads required to achieve it. The scale of assessment has seven bands, from poor quality to international quality virtually throughout a department. Panellists acknowledge uncertainties at the margins but some, at least, assert that departments have been rated with a strong-confidence interval smaller than a band.

But there remain broader questions about the impact of the process. On the positive side, standards as a whole are improving. Over the four years since the previous exercise, universities have decided to invest in some departments to boost their ratings; staff have been pressurized to apply themselves more vigorously to achieving grant income and productivity. The RAE has also led to other tactics new to British academic life. Some high-fliers been bought in at high prices to boost some department performances while, more questionably, other stars have delayed departures for the same reason. No doubt some staff relations have deteriorated and there are allegations that teaching has suffered (although the evidence of the latter is slender, and it is worth remembering that universities are separately rated and rewarded for teaching too).

The pressures in universities are also strong in another sense. Higher education budgets have declined and the United Kingdom's new universities are putting additional pressure on the system. For those reasons, a university that has sustained its departmental rankings will nevertheless receive less money per staff member during the next funding round later this year.

Such stresses may be the price of progress in a time of declining budgets. But other financial impacts also need to be considered. The ratings will have a direct impact on money received for staff and infrastructure from the funding councils, although the formulae to be applied are not yet clear. The university receives the money as a block, so distribution to departments remains at the discretion of the institution (whereby hang some colourful tales of internecine strife). But the RAE has implications for other revenues: studentships from research councils have, on at least one occasion, been deliberately biased to highly rated departments; awards of research grants can also be influenced as, undoubtedly, will be a department's ability to attract industrial and other external support.

The RAE's strong leverage on ability to attract funds should therefore cause concern. It makes all the more questionable the policy of funding councils not to consider appeals against ratings.
But that leverage may also be introducing distortions, favouring those who dream of a superleague of research universities, and undermining a cause that supporters of the RAE tend to celebrate: the ability of newer or poorly endowed departments to improve themselves and thus breed healthy diversity.

\section{Rally behind the NSF}

Scientists should support a proposal to expand the budget of the National Science Foundation by more than 7 per cent.

THE new year opens with some encouraging signs that the scientific community in the United States is waking up to its responsibility to provide more vocal and public support for the National Science Foundation (NSF), the main funding agency for non-biomedical university research in the United States.

The American Chemical Society (ACS), the Federation of American Societies for Experimental Biology (FASEB), the American Physical Society and other groups will work together this spring to persuade the Congress of the importance of the agency (see Nature 384, 393; 1996).

FASEB and the ACS say NSF funding should grow by 7.1 per cent this year, restoring the 6.1 per cent in spending power which FASEB estimates the agency has lost in the past two years, and add a gentle expansion of another one per cent (see page 103). The physicists - pedantic to the last - point out that the second significant figure lacks an empirical basis.

Two years ago, FASEB was mocked for proposing a 10 per cent increase in the budget of the National Institutes of Health (NIH) at a time of national austerity. "Earth to FASEB..." ran the headline in Science (266, 1935: 1994). It turned out that FASEB knew something Science did not: in 1995 and again last year, the NIH attracted increases at and close to the FASEB target.

The NSF is not the NIH, and it will never be treated quite so fondly by the Congress. But the increment that the societies seek on its behalf is much smaller ( $\$ 232$ million, against almost $\$ 1$ billion won last year for NIH), and there is a strong case to be put for it.

Both the Clinton administration and the Congress have spent the past two years preaching the special value of peer-reviewed, university science. They frequently cite the NSF as the model sponsor of such science, and invite other agencies to learn from its example. The administration, meanwhile, produces countless 'reviews' of its $\$ 20$ billion-a-year network of government laboratories, criticizing their wastefulness and excessive overhead costs. These criticisms are then redoubled at congressional hearings.

But neither branch of the government has mustered the courage to rationalize the laboratories and risk derailing the federal gravy train in even one congressional district. What they should do is to subject the laboratory network to real reform, and so release some resources to support the best available university research through the NSF. Clinton is not expected to do this in his budget proposal next month. The community must, therefore, persuade the Congress to choose peer-reviewed science over porkbarrel spending, and restore the NSF's spending power. 